\title{
La Comisión Demográfica Intersecretarial y el problema migratorio del Soconusco en la década de 1930
}

\section{The Inter-secretarial Demographic Commission and the immigration problem in the Soconusco region during the 1930s}

\author{
Luis Gerardo Monterrosa Cubías* \\ doi.org/10.29043/liminar.v20i1.892
}

Resumen: En el presente artículo analizo el trabajo de la Comisión Demográfica Intersecretarial en México, creada por decreto Ejecutivo en 1935. Reviso la política inmigratoria sancionada por los gobiernos posrevolucionarios y el escenario socioeconómico de la frontera sur que los comisionados hallaron cuando arribaron a Tapachula, Chiapas. Asimismo, examino el diagnóstico de su primer jefe, Jorge Ferretis, y los problemas que enfrentaron en su tarea primordial de otorgar la cartilla de naturalización a muchos de los pobladores del Soconusco que vivían en un limbo jurídico. Por medio de los archivos de la Secretaría de Relaciones Exteriores y el Archivo Histórico Municipal de Tapachula, respondo a la pregunta que guió mis pesquisas: ¿por qué el trabajo de la Comisión, programado al inicio para dos años en el Soconusco, se extendió por más de una década?

Palabras clave: migración, cardenismo, política poblacional, fincas cafetaleras, Comisión Demográfica Intersecretarial (México).

Abstract: In this article I analyze the work of the Inter-secretarial Demographic Commission, created in Mexico by executive decree in 1935. I review the immigration policy sanctioned by the post-revolutionary governments and the socioeconomic scenario of the southern border that the commissioners found when they arrived in Tapachula, Chiapas. I also examine the diagnosis of their first supervisor, Jorge Ferretis, and the problems they faced in their primary task of granting naturalization to many Soconusco residents who lived in legal limbo. By examining the archives of the Ministry of Foreign Relations and the Municipal Historical Archive of Tapachula, I answer the question that guided my research: Why was the Commission's work, originally scheduled for two years in Soconusco, extended for more than a decade?

Key words: migration, Cardenas presidency, population policy, coffee farms, Inter-secretarial Demographic Commission (Mexico).

* Beca posdoctoral, asesorado por la Dra. Dolores Camacho Velázquez, en el Centro de Investigaciones Multidisciplinarias sobre Chiapas y la Frontera Sur de la Universidad Nacional Autónoma de México (CIMSUR-UNAM), México

Recibido: 16 de agosto de 2020 Aprobación 25 de mayo de 2021 Publicación: 29 de octubre de 2021

\section{gerardomonterrosa20@gmail.com} (iD) 0000-0002-5846-7418 


\section{Introducción}

$\mathrm{E}$ n marzo de 1935, el presidente Lázaro Cárdenas firmó el decreto de creación de la Comisión Demográfica Intersecretarial. Con esta iniciativa se buscaba solventar un antiguo problema de la frontera sur: el limbo jurídico en el que vivían muchos de sus habitantes por carecer de una nacionalidad desde que la línea divisoria con Guatemala fue establecida finalmente en 1884 y con lo cual algunos pueblos del país vecino quedaron bajo la jurisdicción de México. Para cambiar esta situación, el gobierno cardenista recién ascendido apostó por el trabajo coordinado entre dependencias. La Comisión quedó integrada por un representante de la Secretaría de Relaciones Exteriores, uno del Departamento Agrario y otro de la Secretaría de Gobernación. El delegado de esta última ocuparía la jefatura y su oficina central fue fijada en la ciudad de Tapachula, contando además con cuatro subdelegaciones en Huixtla, Motozintla, Comitán y Unión Juárez.

El objeto de estudio del presente artículo es la Comisión Demográfica Intersecretarial y el entorno en el que realizó su trabajo. En las páginas que siguen examino las disposiciones que los gobiernos posrevolucionarios sancionaron en materia migratoria, el escenario social y económico de la frontera sur que propició la formación de la Comisión y los objetivos que persiguieron con dicha iniciativa, el diagnóstico elaborado por su primer jefe, Jorge Ferretis, y los problemas que los comisionados tuvieron en el Soconusco al momento de cumplir sus metas. Es preciso indicar que la Comisión finalizó sus labores en la región en 1947, alargando un plazo establecido originalmente para dos años. En este escrito me ocupo únicamente de los primeros seis años: desde su instalación en marzo de 1935 hasta finales de 1941, cuando afloraron severas críticas acerca de su desempeño. Esta delimitación responde al problema historiográfico de mi indagación. En efecto, ¿ por qué el trabajo de la Comisión se alargó por más de una década? ¿Qué tipo de problemas diluyeron las estimaciones más optimistas? Para contestar estas preguntas se debe considerar la brecha entre las medidas oficiales, con las que se buscó blindar la frontera al prohibir la inmigración laboral, y una realidad totalmente contraria en la que los trabajadores agrícolas guatemaltecos eran indispensables. ${ }^{1}$

Hasta la fecha, los trabajos en los que se aborda el desempeño de la Comisión y sus desafíos son pocos. Destacan entre estos, por las fuentes de archivo citadas y su coherencia al momento de tejer sus explicaciones, el de Germán Martínez (1994), Manuel Ángel Castillo, Mónica Toussaint y Mario Vázquez (2006) y, finalmente, el de Nidia Cisneros (2015). En el primero se hallan documentos que dan cuenta de los trámites que realizaban los interesados en obtener la cartilla de naturalización, las trabas que tuvieron algunos de ellos y las rencillas que generaba el limbo jurídico en el que vivían numerosos residentes de la región fronteriza. Entretanto, Castillo, Toussaint y Vázquez se refirieron a la oleada de braceros guatemaltecos hacia las fincas del Soconusco en los años treinta, e incluyeron los objetivos de la Comisión, el trabajo efectuado y la extirpación violenta de los referentes identitarios que sufrieron los migrantes, en su mayoría indígenas de la etnia mam, por la campaña de mexicanización que las autoridades implementaron en ese período. En la misma sintonía se encuentra el artículo de Cisneros, quien,

\footnotetext{
${ }^{1}$ La creación de la Comisión Demográfica Intersecretarial respondió, en un contexto más amplio, al interés del cardenismo de defender su territorio y a la política nacionalista desplegada en este período (Knight, 2013, p. 402).
} 
como nota novedosa, efectuó una revisión esquemática de la legislación migratoria de los gobiernos posrevolucionarios, citó algunas reflexiones de sus protagonistas y mostró las diligencias de la Comisión durante su estancia en el Soconusco.

Estos trabajos constituyen referencias obligadas para los estudiosos de la frontera sur, ya que incluyen reflexiones sustentadas en archivos de México y Guatemala que incentivan investigaciones ulteriores. Así surgió, precisamente, el presente trabajo en el que abordo dos aspectos que los autores solo indicaron u obviaron: la política de población del cardenismo que propició la creación de la Comisión y los obstáculos que encaró en el Soconusco al momento de efectuar sus labores. En tal sentido, el objetivo que persigo en este artículo consiste en explicar las directrices de la Comisión y el escenario fronterizo que hallaron para establecer por qué una empresa programada para dos años se extendió por más de un decenio.

Vale la pena subrayar el talante introductorio que posee este trabajo con respecto al desempeño de la Comisión en el complejo entramado de la frontera sur. Aún faltan temas por explorar y archivos que consultar. Entre los primeros sobresale la respuesta de la Secretaría de Gobernación y del Departamento Agrario a los impases planteados por los comisionados, mientras que entre los segundos me faltó consultar el Archivo Histórico del Instituto Nacional de Migración debido a la contingencia sanitaria por el virus SARS-CoV2 que azota el mundo. A pesar de estas carencias, considero que los documentos citados del archivo histórico de la Secretaría de Relaciones Exteriores y del Archivo Histórico Municipal de Tapachula, este último poco visitado por los especialistas, me permitieron elaborar un trabajo que ilumina segmentos que permanecían opacos y aporta temas para el debate historiográfico. Pues bien, el artículo se encuentra dividido en cuatro apartados: en el primero realizo un breve examen del fenómeno migratorio de la frontera sur y las medidas oficiales adoptadas al respecto, en el segundo abordo la política poblacional del cardenismo y los objetivos dictados para la Comisión, en el tercero reviso el diagnóstico de su primer jefe, Jorge Ferretis, y, por último, en el cuarto apartado, examino los avances y las vicisitudes de los comisionados durante sus primeros seis años en el Soconusco.

\section{Los antecedentes}

Durante muchos años el gobierno mexicano le dio la espalda a la frontera sur en el ámbito migratorio. Luego de la firma del tratado limítrofe con Guatemala en 1882, antecedido por intensas disputas y negociaciones, el interés por esta región se fue diluyendo. Una comisión de ingenieros emprendió los trabajos de deslinde, pero la nacionalidad de los pobladores que fueron incorporados a México jamás se estableció. El plazo de un año para efectuarlo caducó sin que se practicara un censo poblacional, incumpliendo el artículo quinto del tratado. Este descuido generó un limbo jurídico en la región fronteriza. Muchos evadían los monumentos que comenzaban a fabricarse para desplazarse al otro lado de una frontera que, además, era mal custodiada. Así lo hicieron los mames de Quetzaltenango, Huehuetenango y San Marcos (Hernández, 2001), cuya emigración hacia el Soconusco se incrementó por dos factores a finales del siglo XIX: primero, por la formación de la economía cafetalera en esa zona y, segundo, por la erupción del volcán Santa María en 1902 que inutilizó varias tierras otrora fértiles en la región suroccidental de Guatemala. El tratado de límites redujo de forma significativa las tensiones internacionales “acerca del Soconusco y abrió el camino para la inversión de capitales" (Spenser, 1988, p. 67), agudizando el limbo jurídico en una frontera abandonada a su suerte. 
Como indicó Germán Martínez, "las primeras inmigraciones guatemaltecas de carácter laboral fueron animadas por aquellos finqueros alemanes que, ante la escasez de tierras y su alto valor en Guatemala, decidieron colonizar tierras chiapanecas para ampliar el cultivo del café" (1994, p. 24). Muchos indígenas emprendieron el viaje y se asentaron finalmente como peones acasillados, atraídos por los jornales pagados en el Soconusco que les brindaban la oportunidad idónea para escapar del trabajo forzado y las leyes contra la vagancia vigentes en Guatemala (Taracena, 2002, p. 292-335). Con el tiempo, los contactos laborales, las historias optimistas sobre el otro lado y las redes familiares propiciaron un flujo migratorio creciente. En 1900 los guatemaltecos constituían el 5.6\% de extranjeros en Chiapas y 30 años más tarde alcanzaron el 16.3\% (Martínez, 1994, p. 26). De hecho, en los años treinta había de cinco a seis mil peones acasillados en la región del Soconusco, "casi todos guatemaltecos, y de 30 a 40 mil trabajadores temporales, de los cuales 10 mil provenían de los Altos de Chiapas y los demás de Guatemala" (Spenser, 1984, p. 5-10).

Es preciso señalar que durante este período la inmigración hacia suelo mexicano fue promovida por el régimen porfirista, el cual sancionó finalmente una ley de puertas abiertas en 1908 para los trabajadores e inversionistas extranjeros. ${ }^{2}$ La medida respondió al aumento de la población foránea, que pasó de 54737 personas en 1895 a 116526 en 1910 (Salazar, 1996, p. 99). Los funcionarios buscaban civilizar el país mediante la incorporación de europeos, acuñando el ideal de Juan Bautista Alberdi, pero debieron conformarse ante la inobservancia de este objetivo con el arribo de trabajadores de otras latitudes para satisfacer la necesidad de mano de obra en el rubro agrícola y la edificación de infraestructura. Una buena ilustración de este dato lo constituye el caso chiapaneco. La inmigración anhelada invirtió su capital en el estado, pero los miles de guatemaltecos que laboraban en las fincas de los pocos alemanes mostraron el verdadero rostro del fenómeno migratorio.

Una vez derrocado el régimen porfirista, y en plena construcción de las instituciones del floreciente Estado, los revolucionarios enfrentaron la inmigración desde una perspectiva diferente. Imperó en su imaginario la usurpación de las riquezas nacionales perpetradas por los extranjeros durante el porfiriato y el deseo de impedir que se repitiera dicho escenario. Por ello, en la Carta Magna de 1917 acotaron derechos y anularon otros que la Constitución de 1857 consagraba a los extranjeros. ${ }^{3}$ Las prohibiciones fueron el "troquel de una legislación migratoria altamente restrictiva a través de la cual se delimitaron los campos donde se desenvolvería la acción de los extranjeros interesados en residir en el país” (Yankelevich, 2011, p. 32). En 1926 promulgaron una Ley de Migración que se orientó a limitar el ingreso de los migrantes y a estipular penalidades para aquellos que no ajustaran su conducta a la nueva disposición. México se incorporó a las discusiones y las prácticas restrictivas que recorrían el continente, como anotó Yankelevich, generando una de las mayores ambigüedades de la era revolucionaria: "bajo un discurso sensible a las injusticias sociales, [...] se alimentó una conciencia étnica excluyente, que condujo a la intolerancia hacia algunas comunidades de extranjeros, pero sobre todo hacia la población indígena” (2011, p. 33).

\footnotetext{
${ }^{2}$ En el caso chiapaneco existe un antecedente: la Ley de Colonización emitida el 15 de diciembre de 1883, con la cual se buscó ocupar los terrenos nacionales aledaños a la recién creada línea fronteriza. "El Soconusco y la Sierra Madre eran para ese entonces zonas escasamente pobladas, por lo que surgió la necesidad de importar trabajadores guatemaltecos y de los Altos de Chiapas en las temporadas de cosecha" (Hernández, 2001, p. 59).

${ }^{3}$ El artículo 33 resulta emblemático, "puesto que además de prohibir a los extranjeros participar en cuestiones de política doméstica, faculta al titular del Ejecutivo a expulsarlos sin necesidad de juicio previo" (Yankelevich, 2011, p. 31).
} 
El nuevo ordenamiento jurídico propició la formación del Departamento Migratorio, el cual fue adscrito a la Secretaría de Gobernación. En adelante, sus personeros investigaron la identidad de los extranjeros residentes en el país, así como las actividades que realizaban (Yankelevich y Chenillo, 2008). Posteriormente, bajo las secuelas de la crisis económica, se legisló una vez más en materia migratoria. En la Ley de 1930 defendieron las bondades de la inmigración, pero la residencia en México quedó reservada para aquellas "razas que, por sus condiciones, sean fácilmente asimilables a nuestro medio con beneficio para la especie y para las condiciones económicas del país" (Yankelevich, 2011, p. 42). La confidencialidad pasó a ser la norma en el funcionamiento del Departamento Migratorio; sus personeros denegaban el ingreso a polacos, chinos, armenios y sirio-libaneses, entre otros, atendiendo las circulares que los calificaban de indeseables. Además, prohibieron desde 1929 la entrada de aquellos extranjeros con intenciones de trabajar en territorio mexicano.

La concreción de estas medidas estuvo plagada de arbitrariedades y corrupción, como lo declaró a través de eufemismos el jefe del Departamento Migratorio, Andrés Landa y Piña. Esos "actos que no tienen calificativo para explicarse" - según sus palabras - habían debilitado el cordón defensivo que serviría para garantizar el trabajo de los nacionales y emplear a los deportados de Estados Unidos (Carreras, 1974). Sin duda, los efectos de la crisis económica exacerbaron las posturas más excluyentes, aquellas que observaron en los braceros foráneos una amenaza. Ahora bien, ¿ se cumplieron estas directrices en el Soconusco? La respuesta es negativa y hunde su raíz en los intereses de los cafeticultores y ciertos políticos de Chiapas, quienes cooptaron a los funcionarios migratorios. Los primeros necesitaban de la inmigración temporal para las cosechas y los segundos utilizaban a los guatemaltecos en su proselitismo. Este escenario fue analizado por los diseñadores de la política migratoria, quienes postularon el limbo jurídico como el meollo del problema de la frontera sur: "la situación ambigua que prevalece consiste en que ciertos núcleos de individuos carecen de toda posibilidad para comprobar su origen mexicano, sin que se les pueda justificar que no lo sean".

Paradójicamente, las nuevas medidas solo dieron cabida a mayores arbitrariedades e injusticias. A principios de los años treinta, la acusación de ser guatemalteco fue usada para dirimir pleitos personales, suscitando deportaciones que no tardaron en incomodar al régimen vecino. Para aliviar la tensión, los gobiernos concertaron una Conferencia sobre migración en agosto de 1932. Los mexicanos se comprometieron a detener las deportaciones arbitrarias y a realizar un censo de los guatemaltecos residentes en la frontera sur. ${ }^{5}$ Luego de la reunión, estos delegados visitaron el Soconusco, epicentro de las disputas abordadas, y plasmaron en sus informes la precariedad y el descuido de esta región. Según el embajador en Guatemala, Gustavo Serrano, era urgente contener la inseguridad que asolaba a sus pobladores y elaborar un proyecto integral en el que participaran diversas dependencias del gobierno federal como el Departamento Agrario y la Secretaría de Educación Pública, de Fomento y Agricultura, así como la cooperación internacional. ${ }^{6}$

\footnotetext{
${ }^{4}$ Informe del jefe de la Comisión Demográfica Intersecretarial, Tapachula, 9 de septiembre de 1935, en AHGE-SRE, exp. III1728-1 (II).

${ }^{5}$ Conferencias Internacionales. Juntas celebradas en la Ciudad de Guatemala sobre asuntos de migración y residentes en el extranjero, México, 5 de septiembre de 1932, en AHGE-SRE, exp. III-1728-1 (I).

${ }^{6}$ Comunicación del embajador mexicano en Guatemala al secretario de Relaciones Exteriores. Informe acerca del viaje a la región del Soconusco, 27 de agosto de 1932, en AHGE-SRE, exp. III-1728-1 (I).
} 
A estas alturas, los problemas de esta región se habían multiplicado. La repartición de tierras estaba en marcha a pesar de la oposición de los terratenientes y la displicencia de las autoridades estatales (Spenser, 1988:279-321), suscitándose acaloradas protestas en las que manifestaban que ciertos beneficiarios eran guatemaltecos. Por otra parte, la Ley Federal del Trabajo, sancionada en 1931, establecía una cuota restringida de extranjeros que se incumplía en las fincas cafetaleras. De esta forma, la nacionalidad se volvió cada vez más relevante en el control de la tierra y la administración de las fuentes de empleo (Nolan-Ferrell, 2013, p. 22). Los agentes migratorios visitaron los cafetales para aplicar dicha normativa, pero incurrieron en diversas ocasiones en las prácticas que los comisionados mexicanos se comprometieron a erradicar en la Conferencia de 1932. Así lo denunció el cónsul guatemalteco en Tuxtla Chico, Chiapas, en octubre de 1934, cuando informó de siete agraristas guatemaltecos que habían sido deportados de la colonia Hidalgo. Los trabajadores, todos indígenas, fueron detenidos ante una queja de los vecinos, y en la breve pesquisa efectuada por los agentes de Migración demostraron que tenían 28 años de vivir en México. A pesar de ello, "las pruebas no fueron tomadas en cuenta y se les deportó acusándolos de estar inmiscuidos en la política de este país y de infracciones a las leyes de Migración”, externó el denunciante. ${ }^{7}$

Ciertamente, la acusación contra los políticos de otorgar tierras a los guatemaltecos a cambio del apoyo en su proselitismo fue frecuente en los albores de los años treinta. Colonias agrarias completas estaban formadas por individuos de esa nacionalidad, según el presidente municipal de Tuxtla Chico, quien lamentaba la usurpación de los derechos reservados para los mexicanos. ${ }^{8}$ Mientras estas irregularidades tenían lugar, la campaña presidencial de 1934 cobraba fuerza. El candidato del Partido Nacional Revolucionario, Lázaro Cárdenas, recorrió algunos municipios chiapanecos acompañado del gobernador del estado, Victórico Grajales. Aquel constató de primera mano la realidad socioeconómica del sureste mexicano, consciente del desafío que aún encaraban de localizar zonas de desarrollo agrícola para ubicar a los braceros provenientes de Estados Unidos. El Soconusco mantenía este estatuto, pero comprobaron que antes necesitaban abordar el ámbito migratorio desde otros parámetros. El equipo de trabajo del candidato atendió las recomendaciones formuladas en las Convenciones sobre Migración, y luego, al triunfar en la elección, conservaron a sus promotores en los puestos, entre ellos a Andrés Landa y Piña. Se habló entonces de una política poblacional, de erradicar la improvisación y coordinar el trabajo de diversas dependencias para abordar los problemas detectados.

\section{Directrices renovadas}

La estrategia del nuevo gobierno contempló la organización de un ente rector para tratar los problemas de la frontera sur. Así, el 18 de marzo de 1935 crearon la Comisión Demográfica Intersecretarial a través del decreto presidencial núm. 682. En el preámbulo aclararon que las dificultades habían surgido antes de que el artículo 11 de la Constitución de 1917 permitiera legislar en materia migratoria, y precisaron que

\footnotetext{
${ }^{7}$ Carta del embajador guatemalteco en México al secretario de Relaciones Exteriores de México, 6 de octubre de 1934, en AHGESRE, exp. III-296-31.

${ }^{8}$ Carta del presidente municipal de Tuxtla Chico al embajador mexicano en Guatemala, 6 de agosto de 1932, en AHGE-SRE, exp. III-1728-1 (I).
} 
estas podían resolverse con los lineamientos jurídicos vigentes. A pesar de este optimismo, reconocieron que en la práctica se presentaban vicisitudes casi insuperables por la falta de pruebas para definir la nacionalidad de numerosos pobladores, "tanto porque carecen de toda documentación, como porque el Tratado de 1882 establece normas especiales para la elección de la nacionalidad de los antiguos habitantes del estado de Chiapas y su distrito del Soconusco". Por esa razón, era urgente emprender una labor conjunta para atacar a fondo los problemas que también desvelaban al gobierno vecino. Con esta convicción se incluyó a la Secretaría de Gobernación, regente del Departamento de Migración, a la Secretaría de Relaciones Exteriores por la comunicación con los funcionarios guatemaltecos y el cumplimiento de los acuerdos alcanzados y, finalmente, al Departamento Agrario que dirimía los conflictos generados en la repartición de tierras.

Es preciso señalar que la adopción de la política poblacional propició cambios a nivel institucional y planes de acción en los ámbitos de la inmigración, la emigración y el fomento natal. Entre los primeros destaca la inscripción del antiguo Departamento de Migración a la recién formada Dirección General de Población y las nuevas atribuciones del Consejo Consultivo Migratorio. Entretanto, en el ámbito inmigratorio suprimieron las circulares confidenciales que daban cabida a la arbitrariedad en la admisión de extranjeros, y priorizaron la entrada de foráneos "fácilmente asimilables a nuestro medio, con preferencia a los de cultura latina; a extranjeros agricultores dotados de cierta preparación cultural y conocimientos especiales en su materia, que ayuden al cultivo de nuestros campos" (Yankelevich, 2011, p. 64). Así, con el objetivo de regular la inmigración, elaboraron tablas diferenciales en las que establecieron la cantidad de individuos de una nacionalidad que admitirían anualmente. En otras palabras, implantaron un modelo de inmigración basado en la selección, dejando claro que en adelante la prioridad de la política demográfica radicaría en el incremento de su población por medio de una abundante natalidad e intensas campañas de persuasión para menguar la emigración hacia Estados Unidos (Carreras, 1974).

En el caso de la frontera sur, los responsables de la política demográfica decidieron proceder por etapas. Primero se ocuparían de la región del Soconusco, plagada de litigios por la repartición de tierras y de braceros temporales que ingresaban ilegalmente desde Guatemala, y luego los comisionados se trasladarían a Quintana Roo, en la frontera con Belice, de donde muchos mexicanos querían regresar. ${ }^{10}$ La Comisión tuvo como objetivo en su primera fase velar por el cumplimiento de las leyes migratorias, impidiendo que el problema demográfico empeorara, así como estudiar y resolver cada caso que fuera sometido a su consideración para establecer la nacionalidad de los residentes del lugar. Sus actividades iniciaron en abril de 1935, cuando el representante del Departamento Agrario, Wilfrido Parra; de la Secretaría de Relaciones Exteriores, Emilio Calderón Puig, y Jorge Ferretis, de Gobernación, acordaron su agenda en Tapachula. ${ }^{11}$ A este último, quien se desempeñaba como jefe de la Comisión, le encomendaron un diagnóstico de la frontera sur.

\footnotetext{
${ }^{9}$ Acuerdo presidencial núm. 682, 18 de marzo de 1935, en AHGE-SRE, exp. III-1728-1 (I).

${ }^{10}$ Origen de la Comisión Demográfica Intersecretarial que funciona en Tapachula, Chiapas, México, 21 de febrero de 1941, en AHGE-SRE, exp. III-1728-1 (IV).

${ }^{11}$ Carta del subsecretario de Relaciones Exteriores al secretario de Relaciones Exteriores de México, 26 de abril de 1935, en AHGE-SRE, exp. III-1728-1 (I).
} 


\section{Las consideraciones del jefe de la Comisión}

Ferretis elaboró un informe de 33 cuartillas que envió en agosto de 1935 a los titulares de las dependencias que integraban la Comisión. Abordó las causas de la inmigración temporal, la situación de la frontera, las fluctuaciones del precio del café en el mercado internacional y su impacto en la economía chiapaneca, la conducta de los finqueros y las autoridades locales ante los migrantes guatemaltecos, la reforma agraria, y realizó una valoración de los indígenas que arribaban de la vecindad. Por las venas del funcionario corría la savia literaria y esto se puso de manifiesto al comunicar con profundidad sus indagaciones. Imprimió a sus páginas una dosis de polémica al describir a los oriundos de esta región en términos peyorativos. ${ }^{12}$ A pesar de esto, el documento resulta valioso porque muestra la perspectiva de quien enfrentó in situ los problemas fronterizos y permite observar cómo respondió ante dos directrices del gobierno federal: el rechazo de trabajadores extranjeros y la selección de los que estaban interesados en residir en el país.

Como puede verse, la política inmigratoria del cardenismo fue altamente restrictiva y controlada. Por una parte, siguió los pasos del gobierno predecesor al cerrarles la puerta a los trabajadores foráneos y, por otra, establecieron el número de extranjeros y las nacionalidades que les interesaba recibir. ${ }^{13}$ Esta tendencia fue plasmada en la Ley General de Población de 1936, en la que desecharon la estrategia de aumentar la población de México a través de la inmigración, para apostar por el fomento de la natalidad y los programas de repatriación de sus emigrados. Las autoridades buscaban proteger las fuentes de empleo de los nacionales, y por ese motivo prohibieron de forma indefinida "la entrada de inmigrantes trabajadores y el ingreso de extranjeros para dedicarse a actividades comerciales, excepción hecha al comercio de exportación (artículos 84 y 87)" (Yankelevich, 2011, p. 47). Mientras estas piezas del tablero se movían, Ferretis encaró una realidad totalmente adversa a las aspiraciones federales. Miles de guatemaltecos cruzaban ilegalmente la frontera para trabajar en las fincas del Soconusco y muchos de ellos se quedaban a vivir en Chiapas ante las irregularidades existentes.

Por esta razón, Ferretis apuntaló en su informe los objetivos de su misión: dictaminar en un plazo máximo de dos años la nacionalidad de aquellos que estaban en un limbo jurídico y frenar la inmigración temporal para dar cabida a los mexicanos que regresaban de Estados Unidos. Sin embargo, las pesquisas realizadas en el terreno hicieron que formulara también algunas observaciones en las que previó una tarea compleja por los intereses contrapuestos y diversos que existían en el lugar. El funcionario inauguró su informe desmintiendo la cifra que se manejaba en la versión popular del núcleo guatemalteco, difundida sobre todo en los rotativos mexicanos: no eran 80000 los que vivían en la zona fronteriza, sino un aproximado de 25 000. En sus indagaciones comprobó que el desplazamiento había aumentado por los efectos de la crisis económica de 1929, pero su origen databa de principios de siglo debido a la erupción del volcán Santa María, ubicado en Quetzaltenango, y al auge cafeticultor en el Soconusco.

\footnotetext{
${ }^{12}$ Jorge Ferretis ha sido ubicado como escritor en la segunda generación de narradores de la Revolución. Sus obras "son producto de la reflexión acerca de la trayectoria que siguen las teorías sociales y su práctica; sobre los ideales y su incumplimiento" (Millán, 1982, p. 28).

${ }^{13}$ Es preciso aclarar que la inmigración española recibió un trato preferente. De hecho, "La Ley de 1936 contenía dos disposiciones que facilitaron la tarea de dotar de un marco normativo a la llegada de los españoles republicanos” (Yankelevich, 2011, p. 75).
} 
Por eso muchas de las personas que entrevistó le contaron que sus padres los habían traído a las cortas de café cuando eran niños, arraigándose finalmente en la zona. ${ }^{14}$

A principios de los años treinta, cuando aumentaron los litigios por el reparto agrario y empezó el registro de los extranjeros en la región, los personeros dividieron a la población en tres grupos: primero, los que conocían su nacionalidad y podían demostrarla sin problema; segundo, los que podían probarla mediante una búsqueda laboriosa de los expedientes y, tercero, aquellos que la ignoraban y no podían investigarla. Uno de los objetivos de la Comisión radicaba, precisamente, en sistematizar y hacer eficiente el trabajo emprendido. Sin embargo, entre los obstáculos por superar, como puntualizó Ferretis, estaba la oposición encarnizada de los finqueros, que habían saboteado el registro desde el comienzo protegiendo a los braceros guatemaltecos. Según la información recabada, a estos les pagaban menos y por eso objetaban las deportaciones bajo el argumento de que su trabajo era indispensable en la agricultura del estado. Además, evitaban el trato con los habilitadores porque asistían voluntariamente a las fincas, a diferencia de los chamulas, "y no creaban dificultad alguna en su calidad de asalariados que no saben protestar", escribió Ferretis.

La predilección de los finqueros seguía vigente cuando los comisionados inauguraron sus actividades, pero su ropaje había cambiado. Si en un principio sobornaban a los agentes migratorios para que callaran o no efectuaran los registros, ahora los propietarios requerían sus servicios para establecer convenientemente quiénes eran foráneos. Este viraje respondió al auge de las organizaciones sindicales que exigían el fraccionamiento de los latifundios y luchaban contra las guardias blancas creadas con el fin de amedrentarlos (Lewis, 2010, p. 448). En otras palabras, los propietarios aprovecharon las disposiciones restrictivas dictadas por el gobierno federal para blandir otra arma: la acusación de ser guatemaltecos ilegales contra los peticionarios de tierras para lograr su deportación. Así sucedió en marzo de 1933, cuando 70 campesinos que se adjudicaron 288 hectáreas de una finca localizada en Motozintla fueron deportados a Guatemala, acusados de permanecer ilegalmente en el país (Gerardo, 2016, p. 57).

Ferretis plasmó en su informe estas anomalías. Supo que los terratenientes empleaban a extranjeros en sus fincas, que se oponían a la reforma agraria y contaban con la complicidad de las autoridades migratorias y estatales. Empero, admitió que la inmigración estacional era imprescindible para que los cafetos no se pudrieran. "La tierra por si sola vale tierra, y solo los factores humanos que en ella se afinquen le darán otro valor que intrínsecamente no tiene”, expresó. Esta confesión contrariaba las directrices emitidas desde el gobierno federal, pero reflejaba una realidad que pudo constatar de primera mano. Los braceros guatemaltecos se adaptaban fácilmente al clima del Soconusco, tenían experiencia en las labores cafetaleras y asistían voluntariamente a la cosecha. Ferretis lamentó que no se hubiera despertado el interés de los nacionales por este rubro y sugirió sustituir gradualmente a los guatemaltecos con las siguientes medidas: mejorar la vigilancia fronteriza, organizar en San Cristóbal de Las Casas un intenso trabajo de preparación "para que los trabajadores acudan por razones de provecho económico al Soconusco y no por ebriedad o de deudas" y, finalmente, autorizar "la inmigración periódica colectiva, documentándola hasta por seis meses y fijar un impuesto equivalente a lo que vale civilizar a cada trabajador chamula". ${ }^{15}$

\footnotetext{
${ }^{14}$ Informe del jefe de la Comisión Demográfica Intersecretarial, 9 de septiembre de 1935, en AHGE-SRE, exp. III-1728-1 (II).

${ }^{15}$ Informe del jefe de la Comisión Demográfica Intersecretarial, 9 de septiembre de 1935, en AHGE-SRE, exp. III-1728-1 (II).
} 
Ferretis abrigaba la esperanza de que más mexicanos llegaran a trabajar a las fincas del Soconusco, pero mientras sucedía tenían que agilizar el proceso de nacionalización de los que así lo solicitaran. Esto lo llevó a reflexionar en la conveniencia de admitirlos, apegándose a uno de los parámetros de la política inmigratoria del cardenismo que conocía con ventajas, pues había participado en las discusiones que antecedieron al diseño de la misma. Como cité en párrafos anteriores, los personeros abrían las puertas del país a los sujetos que se adaptaran con facilidad al medio, de preferencia a los de cultura latina y dotados de alguna preparación técnica para dinamizar el agro mexicano. Sin embargo, Ferretis se topó una vez más en el Soconusco con una realidad totalmente alejada de ese ideal: los indígenas que habían llegado de Guatemala no encajaban en los requerimientos oficiales; al contrario, sufrían muchos de los problemas y las privaciones que empujaban a los mexicanos hacia las plantaciones de Estados Unidos. A pesar de ello, el jefe de la Comisión evaluó con un racismo acentuado "la calidad del factor humano", y calificó a los indígenas como indolentes, reticentes, ignorantes y pobres. Su rechazo fue evidente al momento de explayarse en el informe:

Cuando se tienen a la vista unos centenares de ejemplares humanos de esta región, con una estatura de grandes enanos, una complexión precaria y una capacidad mental lastimosamente atrofiada, cualquier civilizado con salud se sentirá movido a pensar que no vale la pena preocuparse por definir y menos aún por sumar a nuestra nacionalidad semejante contingente de desvalidos. Y hasta se sugeriría (sin poder dar ninguna fórmula de realización) la conveniencia de excluir el mayor número posible. Sin embargo, se imponen algunos considerandos esenciales. ${ }^{16}$

Ferretis apuntó nuevamente lo indispensable que eran para la producción cafetalera, aspecto que compensaba sus taras de inferioridad. Aun así, se refirió a ciertas prácticas de este grupo que le causaban estupor y dificultaban el trabajo de la Comisión. Entre las primeras estaban los matrimonios que los padres concertaban de sus hijas menores de edad. De hecho, mientras recorría la región fronteriza recopilando información presenció el reclamo de unos individuos por el incumplimiento del acuerdo prenupcial. ${ }^{17}$ Ferretis ofreció disculpas por incluir un caso que le restaba seriedad al informe, pero se justificó explicando que tal práctica era frecuente y que violaba las leyes civiles mexicanas. Lo mismo ocurría con los bautizos colectivos que celebraban indistintamente en ambos lados de la frontera durante las fiestas patronales de Tuxtla Chico y Ayutla, Guatemala, acción que impedía la consulta de archivos parroquiales para averiguar el arraigo de los pobladores. En síntesis, el escritor constató que muchos de ellos vivían de espaldas a la frontera y esto, definitivamente, debía cambiar.

Evaluado en retrospectiva, es palpable que Ferretis fue deudor de lo que Yankelevich calificó como una de las mayores ambigüedades del México revolucionario, pues en medio de un discurso sensible a la injusticia social —retratado en su novela El sur quema (1937) —, promovió en su práctica oficial una conciencia étnica excluyente hacia la población indígena (Yankelevich, 2011, p. 32). En ese tono sugirió

\footnotetext{
${ }^{16}$ Informe del jefe de la Comisión Demográfica Intersecretarial, 9 de septiembre de 1935, en AHGE-SRE, exp. III-1728-1 (II).

${ }^{17}$ La querella iba dirigida contra Manuel López, ya que otro padre de familia le había pagado por su hija de 15 años "12 botellas de aguardiente, 3.5 pesos de pan, un peso de chocolate y 50 Ctvs. de cigarros; y a pesar de que la operación se efectuó hace un año, el padre de la muchacha la recogió para negociarle nuevamente". Sobre la celebración de estos matrimonios en Guatemala, puede verse el trabajo de Ricardo Falla (1995) en el que analizó su entramado cultural.
} 
la creación de escuelas sui generis para patojos — como se conoce popularmente a los niños en Guatemala - y chamulas en las fincas cafeteras, donde recibirían "instrucción y racional sustento con cargo al producto de un mínimo de trabajo infantil, sin contrariar el espíritu del artículo 123 Constitucional”. ${ }^{18} \mathrm{El}$ objetivo, como apuntó en su informe, era combinar una educación básica que contemplara la enseñanza del idioma español para impedir que los indígenas fueran engañados y remediar el estupor que embargó a Ferretis cuando no pudo comunicarse con ellos. Pero antes de emprender este tipo de proyectos era indispensable ordenar la casa. Primero debían acabar con las condiciones que hacían incontenible la inmigración temporal, prohibida por la Ley de Migración vigente, y después comprobar el arraigo de los habitantes de la región fronteriza para definirlos como connacionales por naturalización o por opción u origen, sin dejar de considerar en el primero de los casos el grado de deseabilidad. ${ }^{19}$

Ciertamente, la empresa que los comisionados tenían por delante era desafiante, pues al compás de la descoordinación de los agentes migratorios y su arbitrariedad había crecido el número de guatemaltecos residentes en Chiapas: 16 385, según el censo de 1930 citado por Ferretis en su informe, de los cuales muchos carecían de un estatus migratorio regular. Aun así, el jefe de la Comisión desoyó a quienes desacreditaron a priori sus propósitos, trayendo a colación la influencia de los cafeticultores en las esferas gubernamentales. El funcionario conocía la necesidad práctica de solucionar los problemas de la frontera sur y confiaba en el compromiso de las dependencias involucradas. Finalmente, el diagnóstico fue remitido a sus titulares en septiembre de 1935 y seis meses más tarde iniciaron de lleno sus labores.

\section{Entre avances y vicisitudes}

Como expliqué anteriormente, la Comisión Demográfica Intersecretarial fue organizada para establecer la nacionalidad de los pobladores de la frontera sur que vivían en un limbo jurídico. Constituyó una respuesta renovada a problemas antiguos y gestionó un proyecto en el que se buscaba ordenar una región desatendida por años. Los comisionados instalaron su oficina en la llamada "perla del Soconusco", Tapachula, desde donde dirigieron el quehacer de sus empleados y coordinaron esfuerzos con el Departamento Agrario y la Dirección General de Población. Gracias a la correspondencia e informes que emitieron, es posible describir sus diligencias. En efecto, desde marzo de 1936, los agentes de la Comisión atendían a quienes visitaban sus oficinas, pero también se desplazaban a los poblados fronterizos para entrevistar a los jefes de familia. Los sujetos interesados en tramitar su cartilla de nacionalización eran interrogados bajo protesta de ley y demás formalidades; después, los agentes acudían al Registro Civil o a la parroquia del sitio para corroborar los datos brindados. Como en muchas ocasiones dichas pruebas no existían, pedían información al presidente municipal o recurrían, en última instancia, al testimonio de los vecinos.

Una parte de los vestigios de estas diligencias se encuentran en el Archivo Municipal de Tapachula, donde se resguardan las peticiones de información que el jefe de la Comisión dirigió al presidente mu-

\footnotetext{
${ }^{18}$ Informe del jefe de la Comisión Demográfica Intersecretarial, 9 de septiembre de 1935, en AHGE-SRE, exp. III-1728-1 (II).

${ }^{19}$ Ferretis era consciente de que las facilidades para nacionalizarse mexicano podían generar un flujo constante de guatemaltecos. Para evitarlo sugirió redoblar la seguridad de la frontera y valerse de la Ley de Identificación Personal, sancionada en enero de 1933, para dotar de un documento a los ciudadanos y así impedir que la labor resultara interminable. Informe del jefe de la Comisión Demográfica Intersecretarial, 9 de septiembre de 1935, en AHGE-SRE, exp. III-1728-1 (II).
} 
nicipal de Tapachula, así como sus respuestas. En la correspondencia aparecen los datos requeridos y los parámetros aplicados para encauzar o denegar el trámite. Un ejemplo del primer tipo se dio en octubre de 1940, cuando solicitaron la nacionalidad con la que era conocido Vicente Fuentes, su dirección, el tiempo de vecindad y su conducta. En la misiva precisaron que "en caso de no ser conocido en esa presidencia a su digno cargo, le estimaré tomar informes del lugar donde vive el interesado, comunicando los datos que haya obtenido" ${ }^{20}$ La respuesta arribó semanas más tarde: Fuentes era guatemalteco y tenía cinco años de residir en Tapachula y buena conducta. Distinta fue la resolución en el caso de Pedro Yoc, de origen guatemalteco, quien fungía como administrador de la finca Los Ángeles. Yoc llevaba una década de residir en el Soconusco, pero su naturalización fue rechazada porque tenía una multa de la Secretaría de Hacienda. ${ }^{21}$

Es importante indicar que los comisionados tenían instrucciones precisas de respetar los derechos de los ciudadanos guatemaltecos en estas diligencias, ahorrándose las disputas con el gobierno vecino. Por eso se había incluido a un representante de la Secretaría de Relaciones Exteriores, para que la resolución del problema migratorio de la frontera sur se basara en una relación bilateral honesta y sana. Así lo externaron los delegados mexicanos durante la Conferencia de 1932, y lo reiteraron tres años más tarde ante los vientos favorables que soplaban en Guatemala. Por primera ocasión las declaraciones y acciones del presidente guatemalteco Jorge Ubico coincidían para evitar que sus ciudadanos se marcharan a trabajar al Soconusco. Su gobierno había reforzado la vigilancia de la campiña guatemalteca en 1934, redefiniendo la Ley contra la Vagancia. ${ }^{22}$

En este punto debe señalarse que Ubico administró los efectos de la crisis económica por medio de una política de austeridad y confiando en la pronta recuperación de los precios del café en el mercado internacional. Con el tiempo su esperanza se hizo realidad, y entonces recurrió al trabajo forzado para asegurar las cosechas en las plantaciones de la Bocacosta. Asimismo, redobló la vigilancia de la frontera con México y pidió a ese gobierno que deportara a muchos mozos que tenían deudas en Guatemala (Martínez, 1994, p. 44).

Los comisionados y su equipo parecían tener mucho a su favor. Era clara la voluntad gubernamental de suprimir el limbo jurídico de la frontera sur, de proporcionar los recursos necesarios y colaborar con un régimen vecino a pesar de la desconfianza que externaba hacia México. Sin embargo, muy pronto, la realidad de una región donde prevalecían intereses diversos y contrarios al ordenamiento programado los golpeó con fuerza. En este sentido, si el diagnóstico de Ferretis destiló optimismo al inicio de sus labores, el informe de Contreras, quien sustituyó al escritor en la jefatura de la Comisión, mostró meses más tarde el tremedal por el que caminaban. Más allá del compromiso asumido por los funcionarios de acabar con los vicios arraigados, siguieron gestándose deportaciones arbitrarias, contrataciones ilegales de braceros guatemaltecos y la cooptación de muchos de ellos en las campañas proselitistas de Chiapas.

\footnotetext{
${ }^{20}$ Carta del jefe de la Comisión Demográfica Intersecretarial al presidente municipal de Tapachula, 21 de octubre de 1940, presidencia municipal, caja 7, exp. 23, en Archivo Histórico Municipal de Tapachula (en adelante AHMT).

${ }^{21}$ Carta del jefe del Departamento Agrario al jefe de la Oficina Federal de Hacienda, Chiapas, 21 de noviembre de 1940, presidencia municipal, caja 7, exp. 23, en AHMT.

${ }^{22}$ Sobre el contexto social, político y económico de esta redefinición véase (McCreery, 2001: 347-384).
} 
En marzo de 1937, los directivos de la Federación Distrital Obrera y Campesina del Soconusco enviaron una denuncia a la Comisión Demográfica, que cumplía un año de haber arrancado su faena. Expresaron que agentes de Migración a cargo de Francisco Niño habían llegado a la finca La Unidad del municipio de Cacahoatán, donde procedieron a aprehender a 26 trabajadores para expulsarlos con su familia del país. El carácter injusto de esta situación, como especificaron los denunciantes, era que los trabajadores de la finca estaban tramitando su cartilla de naturalización, restando solo el aval del delegado de la Secretaría de Relaciones Exteriores para obtenerla. ${ }^{23}$ La respuesta del jefe de la Comisión no se hizo esperar. Se dirigió al jefe del Servicio de Población de Tapachula para solicitarle que los agentes interrumpieran estas acciones que obstruían su labor y violaban el acuerdo suscrito con Guatemala de detener las deportaciones mientras la Comisión ordenaba el estatus migratorio de la frontera sur.

Mientras este tipo de anomalías se suscitaban, los braceros guatemaltecos continuaron cruzando la frontera para trabajar en el Soconusco. Así, el temor de los comisionados de que su labor cayera en una repetición incesante, cual mito de Sísifo, cobraron vigencia debido a las inagotables solicitudes de nacionalización de los migrantes. De hecho, los maestros de la escuela socialista destacados en Chiapas denunciaron la presencia de los braceros vecinos, arguyendo que remplazaban a los mexicanos, cobraban menos y soportaban los malos tratos de los finqueros porque ignoraban las leyes de trabajo (Lewis, 2010, p. 451). Para corroborar estas denuncias, la Secretaría de Defensa organizó un operativo en la frontera a mediados de octubre de 1940. El comandante militar de Tapachula informó al secretario de Gobernación, Ignacio García Téllez, que sus elementos observaron cómo los guatemaltecos se movían por veredas rumbo a las fincas cafetaleras, calculando que se trataba de unos diez mil hombres. "Sólo con la ayuda de las fuerzas federales podría evitarse la internación clandestina —explicó el militar-, pero esto puede ser mal interpretado por el gobierno de Guatemala".24

El flujo constante de guatemaltecos hacia el Soconusco muestra que las disposiciones punitivas de Ubico resultaron insuficientes, pero exhibe además el prurito de los funcionarios mexicanos por evitar cualquier malentendido con aquel gobierno. Al final, los beneficiados fueron los indígenas que cruzaban la frontera por los puntos ciegos de San Marcos y Huehuetenango; fugitivos en su patria, pero apetecidos en Chiapas y contratados por los finqueros como trabajadores voluntarios. Miles de familias que "traspusieron las fronteras artificiales que antes de 1882 no existían, que se asimilaron a una cultura común y encontraron allá satisfacciones económicas vitales que el sistema nuestro ha sido incapaz de brindar" (Fernández, 1992, p. 3). En junio de 1941, el gobernador chiapaneco, Rafael Pascacio Gamboa, efectuó una gira por la región fronteriza del estado. Días más tarde, le escribió al secretario de Relaciones Exteriores preguntándole si existía completa libertad para que los guatemaltecos penetraran al país, "pues cuentan con todas las facilidades para nacionalizarse, desplazando a los campesinos mexicanos".25

Sin duda, este escenario contradecía por completo las directrices federales vigentes desde los años treinta. Lanzaba por la borda la intención de cerrar la válvula de la inmigración ilegal y el proyecto de

\footnotetext{
${ }^{23}$ Transcripción de oficio de la Federación Distrital Campesina y Obrera del Soconusco, Tapachula, 24 de marzo de 1937, en AHGE-SRE, exp. III-1728-1 (IV).

${ }^{24}$ Informe del comandante militar de Tapachula al ministro de Gobernación, Chiapas, 18 de octubre de 1940, en AHGE-SRE, exp. III-432-27.

${ }^{25}$ Carta del gobernador del estado de Chiapas remitida al secretario de Relaciones Exteriores de México, Tuxtla Gutiérrez, 16 de junio de 1941, en AHGE-SRE, exp. III-432-27.
} 
mexicanizar la frontera sur. Pese a todos los discursos y disposiciones emitidas, las autoridades seguían reportando la entrada constante de familias guatemaltecas por el municipio fronterizo de Unión Juárez y la existencia de colonias como Santo Domingo, donde los líderes ejidales eran sujetos de esa nacionalidad que celebraban las fiestas cívicas izando la bandera con el escudo del quetzal. ${ }^{26}$

La situación descrita me permite retomar el tema del presente artículo y formular un interrogante acerca del desempeño de la Comisión. En efecto, ¿por qué su trabajo no tuvo la incidencia proyectada en la dinámica de la frontera sur? Se trata de una respuesta compleja, pero quiero aprovechar las pistas que entresaqué de los documentos consultados para esbozar la siguiente tesis: la Comisión trabajó en medio de la convulsión agraria del Soconusco y encaró sus problemas rodeada de un personal displicente, escaso y viciado que entorpeció su trabajo: agentes migratorios, presidentes municipales y otras autoridades que sacaban raja del desorden reinante y colaboraban con los finqueros y políticos locales que boicoteaban la regularización estipulada.

Las primeras señales de las carencias que tenía la Comisión surgieron un año y medio después de haber iniciado sus labores. En julio de 1937 su jefe calculó que faltaba dictaminar la nacionalidad de 126000 personas, y explicó que el procedimiento era engorroso porque los interesados no daban la documentación e información requeridas, pues, según sus palabras, "son gente sumamente ruda perteneciente a la raza indígena e incapaces de arrojar luces al respecto".27 A pesar de estas dificultades, precisó que habían estudiado 12200 expedientes, y aclaró que si a ese número sumaban el de sus familias tenían controlados a unos 50000 individuos, es decir, poco menos de la mitad de los existentes en la región. Sin embargo, era urgente que les asignaran doce empleados más, cuatro por cada dependencia involucrada en la Comisión, para cubrir la extensa localidad de Motozintla y redoblar su trabajo en los pueblos de Suchiate y Unión Juárez. Como puede inferirse, la escasez de personal era un impase que podía superarse, pero existían otros que requerían mucho más que un refuerzo presupuestal.

Germán Martínez aludió en su trabajo al cohecho y a la perversión suscitados durante el proceso de nacionalización iniciado en 1936 (Martínez, 1994, p. 47); y sus pruebas, en efecto, se encuentran en los informes de sus responsables. Un ejemplo son las actas de nacimiento fraudulentas que los guatemaltecos compraban a las autoridades municipales. Así lo refirió Jorge Ferretis en su diagnóstico cuando expuso el caso del alcalde de Cacahoatán, quien, al enterarse del arribo de la Comisión, le consultó al delegado del Departamento Agrario qué nacionalidad quería que adoptaran los habitantes de su jurisdicción, pues tenía la capacidad de acreditarlos legalmente como mexicanos o guatemaltecos. ${ }^{28}$ En este renglón destacaron también ciertos delegados de la Oficina de Población que por su arbitrariedad se enfrascaron en pleitos acalorados con los cónsules guatemaltecos.

En mayo de 1937, un agente de esa Oficina destacado en Tuxtla Chico informó a su superior que el cónsul guatemalteco de dicha localidad lo había insultado en varias ocasiones, enfurecido porque cumplía a cabalidad con su trabajo. El denunciante expresó que hasta esa fecha tenía en su haber 32 deportaciones

\footnotetext{
${ }^{26}$ Informe del presidente municipal de Unión Juárez al gobernador del estado de Chiapas, 23 de julio de 1941, en AHGE-SRE, exp. III-432-27.

${ }^{27}$ Petición del jefe de la Comisión Demográfica Intersecretarial relativa al aumento de personal en esa oficina, Tapachula, 2 de julio de 1937, en AHGE-SRE, exp. III-1728-1 (IV).

${ }^{28}$ Informe del jefe de la Comisión Demográfica Intersecretarial, 9 de septiembre de 1935, en AHGE-SRE, exp. III-1728-1 (II).
} 
de braceros vecinos que les quitaban el trabajo a los chamulas, y eso era lo que el agente consular no le perdonaba. ${ }^{29}$ Un mes después de haberse presentado esta queja, el canciller de la embajada mexicana en Guatemala recorrió la región del Soconusco para conocer de primera mano las trabas que los mexicanos experimentaban para ingresar a la nación vecina. Conversó en Tapachula con el jefe del Servicio de Población, Francisco Niño, quien le comunicó que las dificultades con el referido cónsul se debían a la inflexibilidad y falta de tacto del denunciante, Pardo Gaxiola, quien se había peleado también con el presidente municipal de Tuxtla Chico debido a las deportaciones arbitrarias. En vista de lo anterior, Niño pidió su traslado para acabar con el conflicto, pues, lejos de la abnegación presumida por Gaxiola en su querella, se trataba de un sujeto problemático.

Luego de esta entrevista, el canciller Armando González se dirigió a la estación de Tapachula, donde tomaría el tren con destino a Mariscal. El paso de la máquina proveniente de Veracruz estaba programado para las 16:30, pero llegó con tres horas de retraso. González entró en el hotel al filo de la medianoche y preguntó dónde descansaba la tripulación del tren. El recepcionista le proporcionó el dato y le dijo que podía encontrarlos a esa hora en la fonda de enfrente. Sin revelarles su identidad, el diplomático se puso en contacto con el maquinista y el fogonero, quienes le confesaron al calor de la plática que la dilación era una maniobra para cobrar horas extras. "Hice ver al maquinista —escribió González- que en Guatemala se multa a los conductores que no llegan a la hora precisa del itinerario; a esto me contestó que por algo había adelantado en este sentido el obrerismo mexicano". ${ }^{30}$

El canciller se despidió de los comensales y partió al día siguiente rumbo a Suchiate. Allí encontró otra sorpresa desagradable. Decidió visitar por la noche al responsable de la Oficina de Población del municipio, ya que le había comunicado por telegrama su llegada. Sin embargo, la puerta jamás se abrió y solo se escuchó una voz masculina que refunfuñaba seguida de los gritos de una mujer que explicaba que el señor estaba borracho. "A la mañana siguiente me presenté en la misma oficina —explicó Gonzálezy fui recibido por Eugenio Leyva en cuyo aspecto se advertía aún su estado de ebriedad". Cuando selló su pasaporte le dijo que le extrañaba que no llegara a buscarlo la noche anterior, a lo que el diplomático respondió que lo había hecho, pero la sirvienta le informó que estaba bebido. La confesión le causó un enorme disgusto a Leyva, quien reprendió severamente a la empleada.

En síntesis, los casos reseñados muestran la conducta inadecuada que tenían muchos de los responsables de ejecutar las disposiciones inmigratorias. La displicencia y la corruptela que el mismo jefe de la Comisión atribuyó al desorden imperante en 1937, sin reconocer que eran estos funcionarios quienes lo promovían y se beneficiaban de él. "Esa situación ha dado oportunidad a las autoridades municipales, a los jueces del Registro Civil y a las autoridades de migración —escribió Contreras- para explotar a los interesados en definir su nacionalidad, muchas veces hasta de una manera inmoderada y en grande escala, como lo he probado con documentos fehacientes". ${ }^{31}$ Estos señalamientos invadieron, incluso, el seno de la Comisión cuando el embajador de México en Guatemala denunció que sus empleados exigían

\footnotetext{
${ }^{29}$ Comunicación del jefe del Servicio de Población de Tapachula al secretario de Relaciones Exteriores de México, 6 de mayo de 1937, en AHGE-SRE, exp. III-1728-1 (IV).

${ }^{30}$ Informe del canciller de la embajada de México en Guatemala sobre diversos asuntos de la frontera, en AHGE SRE, exp. III-1728-1 (IV).

${ }^{31}$ Petición del jefe de la Comisión Demográfica Intersecretarial relativa al aumento de personal en esa oficina, Tapachula, 2 de julio de 1937, en AHGE-SRE, exp. III-1728-1 (IV).
} 
pagos en efectivo a las personas que realizaban diversos trámites. Contreras se limitó a confirmar su honradez y compromiso, pero aclaró que como sus subalternos recorrían los poblados sin que él estuviera presente, no metía las manos al fuego por nadie. ${ }^{32}$

Al final, este tipo de comportamiento terminó minando el trabajo de la Comisión, el cual estaba programado originalmente para dos años y se extendió hasta 1947. El caso refleja la brecha generada en ocasiones entre las directrices oficiales y su ejecución. Por un lado, era evidente el interés de los diseñadores de la política migratoria de frenar el ingreso de braceros guatemaltecos y eliminar el limbo jurídico de la frontera sur; pero, por otro, estaba claro que para lograrlo los comisionados debían plantar pelea a los poderes fácticos del Soconusco. Y fue aquí, precisamente, donde las medidas sancionadas desde Ciudad de México chocaron con la realidad de una región que bien puede describirse con un dicho popular: en río revuelto ganancia de pescadores. En efecto, la Comisión fue instaurada en una época muy agitada, marcada por la oposición de los finqueros a la reforma agraria, el apogeo sindical y agrarista, la represión del gobernador Victórico Grajales a estas organizaciones (Benjamin, 1995, p. 203) y los pleitos suscitados por la escasa tierra repartida. No cabe duda de que pisaron un terreno minado en el que la indefinición jurídica de sus pobladores y el ingreso ilegal de los braceros vecinos coadyuvaron para que los finqueros y políticos chiapanecos alcanzaran sus objetivos: mano de obra barata, voluntaria, y respaldo electorero.

\section{Conclusiones}

En las páginas anteriores he citado en diversas ocasiones la obra de Germán Martínez (1994), pionera en el abordaje del problema migratorio de la frontera sur desde fuentes archivísticas. Entre sus virtudes destacan las conexiones que entabla con la realidad política guatemalteca de los años treinta y las conclusiones que establece. Quiero detenerme, por cierto, en una de estas últimas. Al final del apartado que dedicó a la Comisión Demográfica Intersecretarial, escribió que la inmigración temporal y definitiva no se detuvo por la vecindad, por el nexo laboral en torno a la economía cafetalera y el continuo transcurrir de períodos militares en el gobierno de Guatemala en un contexto de deterioro económico. Martínez acertó al postular como factores de este flujo las condiciones del país vecino y los vasos comunicantes que el trazo fronterizo no erradicó. En este último punto me detendré para contestar la pregunta de investigación que formulé en la introducción de este artículo.

Como apreció el lector, en los apartados precedentes expuse la postura del gobierno mexicano sobre la frontera sur, sus proyectos y los objetivos que contemplaron al organizar la Comisión a mediados de los años treinta. Esta forma de tratar la problemática responde a una estrategia narrativa basada en las fuentes primarias consultadas. Sin embargo, esta cara de la moneda tiene su anverso. No se debe perder de vista que la línea fronteriza se estableció a finales del siglo XIX, dividiendo una zona que permaneció comunicada durante siglos por lazos familiares y redes comerciales (Taracena, 2009). En tal sentido, las medidas impositivas del régimen posrevolucionario, que incluían una campaña de mexicanización en la frontera con Guatemala, chocaron con una realidad difícil de erradicar a través de decretos: los vasos comunicantes de los mames, jakaltecos, k’anjobales y chujes (Limón, 2009), en cuyos terrenos se trazó

\footnotetext{
${ }^{32}$ Carta del jefe de la Comisión Demográfica Intersecretarial al secretario de Relaciones Exteriores de México, Tapachula, 8 de febrero de 1941, en AHGE-SRE, exp. III-1729-9.
} 
una línea ignorada por estos pobladores, pero que las autoridades de ambas naciones pretendieron blindar en el decenio de los treinta. Por este motivo, y ante una perspectiva de largo aliento, cabe preguntar: ¿quiénes estaban invadiendo el espacio de quién desde el punto de vista de las comunidades indígenas? ${ }^{33}$

De hecho, Jorge Ferretis observó a su llegada que los braceros seguían cruzando hacia el Soconusco, huyendo de los alcaldes que los enviaban a trabajar a las fincas de la Bocacosta guatemalteca por un jornal menor del que ganaban en México. El funcionario formuló en su diagnóstico una serie de recomendaciones para que las disposiciones federales que prohibían la inmigración estacional se cumplieran. Pero también incluyó una afirmación que develó la complejidad de esa región: los vecinos eran indispensables en la producción cafetalera y, por lo tanto, su remplazo debía ser escalonado.

Sin embargo, este recambio jamás se dio debido a la reticencia de los finqueros, que preferían trabajadores voluntarios que cobraban menos y no estaban sindicalizados. De esta forma, el peor de los escenarios presagiado por Ferretis en su informe se cumplió, aunque no le tocó encararlo. Las solicitudes de nacionalización aumentaron constantemente porque los guatemaltecos continuaban cruzando la frontera, aprovechando la corrupción y displicencia de la autoridad estatal y migratoria para regularizar su estatus. Paradójicamente, el trabajo de la Comisión empezó a ser observado con recelo por parte del gobierno vecino, el cual, ante las facilidades otorgadas para que sus ciudadanos se nacionalizaran mexicanos, envió tropas a vigilar la frontera en septiembre de 1936 con el pretexto de combatir el contrabando. ${ }^{34} \mathrm{Al}$ final, la Comisión avanzó entre obstáculos en su encargo y con un retraso que debe explicarse considerando el enorme poder ejercido por los finqueros del Soconusco y las irregularidades que las autoridades practicaban para favorecerlos.

\section{Referencias}

Benjamin, T. (1995). Chiapas: tierra rica, gente pobre. Historia politica y social. Grijalbo.

Carreras, M. (1974). Los mexicanos que devolvió la crisis 1929-1932. Secretaría de Relaciones Exteriores.

Castillo, M. A., Toussaint, M. y Vázquez, M. (2006). Espacios diversos, historia en común. Secretaría de Relaciones Exteriores.

Cisneros, N. (2015). La estrategia federal de regularización de los jornaleros guatemaltecos. Con-Temporánea, 4. https://con-temporanea.inah.gob.mx/del_oficio/nidia_cisneros_num4

Falla, R. (1995). Quiché rebelde. Editorial Universitaria de Guatemala.

Fernández, O. (1992). La migración de trabajadores de Guatemala a Chiapas, México [tesis de licenciatura, Universidad de San Carlos de Guatemala, no publicada].

Ferretis, J. (1937). El sur quema. Ediciones Botas.

Gerardo, S. (2016). Trabajar y vivir entre el cafetal. Los jornaleros de San Marcos, Guatemala en el Soconusco [tesis de maestría, Centro de Investigaciones y Estudios Superiores en Antropología Social, no publicada].

Hernández, R. A. (2001). La otra frontera. Identidades múltiples en el Chiapas poscolonial. Centro de Investigaciones y Estudios Superiores en Antropología Social; Miguel Ángel Porrúa.

Knight, A. (2013). Repensar la Revolución mexicana, t. l. El Colegio de México.

Lewis, Stephen (2010). Una victoria pírrica en el México posrevolucionario: los finqueros alemanes, las escuelas Artículo 123 y la formación del Estado en la costa de Chiapas, 1934-1942. Anuario de Estudios Americanos, 67(2), 445-465.

\footnotetext{
${ }^{33}$ Agradezco a Justus Fenner por la lectura atenta de este artículo y las sugerencias formuladas.

${ }^{34}$ Carta del canciller de la embajada de México en Guatemala al secretario de Relaciones Exteriores de México, Tapachula, 19 de septiembre de 1936, en AHGE-SRE, exp. III-1728-1 (IV).
} 
Limón Aguirre, F. (2009). Historia chuj a contrapelo. Huellas de un pueblo con memoria. Gobierno del Estado de Chiapas; El Colegio de la Frontera Sur.

Martínez Velasco, G. (1994). Plantaciones, trabajo guatemalteco y política migratoria en la frontera sur de México. Gobierno del Estado de Chiapas; Instituto Chiapaneco de Cultura.

McCreery, D. (2001), Mano de obra asalariada, trabajo libre y leyes contra la vagancia: la transición al capitalismo en Guatemala, 1920-1945. En William C. Roseberry y Lowell Gudmundson (eds.), Café, sociedad y relaciones de poder en América Latina. Heredia, Editorial Universidad Nacional.

Millán, M. C. (1982). Antología de cuentos mexicanos. Nueva Imagen.

Nolan-Ferrell, C. (2018). La construcción de la ciudadanía. Los trabajadores transnacionales y la Revolución en la frontera México-Guatemala, 1880-1950. Centro de Investigaciones Multidisciplinarias sobre Chiapas y la Frontera Sur-Universidad Nacional Autónoma de México.

Salazar Anaya, D. (1996). La población extranjera en México (1895-1990). Un recuento con base en los Censos Generales de Población. Instituto Nacional de Antropología e Historia.

Spenser, D. (1984). Trabajo forzado en Guatemala, bracerismo guatemalteco en Chiapas. Cuicuilco. Revista de la Escuela Nacional de Geografía e Historia, 12, 5-10.

Spenser, D. (1988). Los inicios del cultivo del café en Soconusco y la inmigración extranjera. En B. Von Mentz, R. Pérez Montfort, V. Radku y D. Spenser, Los empresarios alemanes, el Tercer Reich y la oposición de derecha a Cárdenas. Centro de Investigaciones y Estudios Superiores en Antropología Social.

Taracena, A. (2002). Etnicidad, Estado y nación en Guatemala, 1808-1944, t. 1. Centro de Investigaciones Regionales de Mesoamérica.

Taracena, A. (2009). Desplazamientos y exilios mayas en la Guatemala decimonónica. En M. Ruz, J. García y A. Ciudad Ruiz (eds.), Diásporas, migraciones y exilios en el mundo maya. Sociedad Española de Estudios Mayas; Universidad Nacional Autónoma de México.

Yankelevich, P. (2011). ¿Deseables o inconvenientes? Las fronteras de la extranjería en el México posrevolucionario. Escuela Nacional de Antropología e Historia; Bonilla Artiga Editores; Universidad Iberoamericana.

Yankelevich, P. y Chenillo, P. (2008). El Archivo Histórico del Instituto Nacional de Migración. Desacatos, $26,25-42$. 